\title{
Dynamic Analysis and Looseness Evaluation of Bolted Connection Under Vibration of Machine Tools
}

\section{Wenxiang $\mathrm{Xu}$}

Beijing University of Technology

Qiang Cheng ( $\sim$ chengqiang@bjut.edu.cn )

Beijing University of Technology

\section{Congbin Yang}

Beijing University of Technology

\section{Ying Li}

Beijing University of Technology

\section{Research Article}

Keywords: Machine vibration, Numerical simulation, Bolt preload attenuation, Working factors, Quadratic general rotary unitized design

Posted Date: May 28th, 2021

DOI: https://doi.org/10.21203/rs.3.rs-548643/v1

License: (c) (i) This work is licensed under a Creative Commons Attribution 4.0 International License. Read Full License

Version of Record: A version of this preprint was published at The International Journal of Advanced Manufacturing Technology on July 29th, 2021. See the published version at https://doi.org/10.1007/s00170-021-07615-0. 


\title{
Dynamic analysis and looseness evaluation of bolted connection
}

\section{under vibration of machine tools}

\author{
Wenxiang $\mathrm{Xu}^{1,2}$, Qiang Cheng ${ }^{1,2, \#}$, Congbin Yang ${ }^{1,2}$, Ying $\mathrm{Li}^{1,2}$ \\ ${ }^{1}$ Institute of Advanced Manufacturing and Intelligent Technology, Beijing University \\ of Technology, Beijing 100124, China
}

${ }^{2}$ Beijing Key Laboratory of advanced manufacturing technology, Beijing University of

Technology, Beijing 100124, China

\# Corresponding author / E-mail: chengqiang@bjut.edu.cn; TEL: +86-15901009350

\begin{abstract}
Bolted connections are widely used in the machine tool manufacturing and equipment. As it is well known, bolt preload will be attenuated by the vibration of machine tools, which will degenerate the working life of machine tools. In this paper, a new experimental design method is introduced into the study on bolt preload attenuation: the quadratic general rotary unitized design. The dynamic analysis of the bolted connection is carried out based on a finely fragmented numerical model to interpret the generation of fretting slip and the reason for the loosening of bolts. The alternating load cyclic vibration test, implemented on the bolted joints, can provide the vibration response under the influence of different working factors. Statistical test and analysis are performed on the quadratic regression mathematical model of the bolt preload attenuation, and the principal working factor that affecting the bolt preload attenuation under vibration can be obtained. Based on the analytical result, the combination of the working factors at the lowest bolt preload attenuation rate, which can effectively slow the bolt looseness, is investigated. The results of this study can provide an experimental basis for improving the machining stiffness of machine tools.
\end{abstract}

Keywords: Machine vibration; Numerical simulation; Bolt preload attenuation; Working factors; Quadratic general rotary unitized design

\section{Introduction}

$\mathrm{CNC}$ machine tools are the core equipment for lightweight and high-precision production of key components in the high-end equipment manufacturing industry and the assembly form is mainly bolted connection. The bolted connection has the characteristics of strong bearing capacity and easy to be disassembled. However, the accompanying vibration during the service of the machine tool is bound to aggravate the loosening of the bolted connection, which will affect the dynamic 
characteristics of the machine tool and ultimately lead to degenerate the machining stiffness and maintainability of the machine tool [1-3]. The factors affecting the bolt looseness involve various aspects such as machining methods, assembly processes, material mechanical properties, and operation conditions, while their coupling effects exacerbate the degree of bolt preload attenuation, further complicating the bolt looseness problem [4-6]. Therefore, in order to meet the requirements of machining stiffness retention in $\mathrm{CNC}$ machine tools, it is necessary to study the working factors and the relaxation mechanism that affect the bolt preload force attenuation.

In response to this problem, domestic and foreign scholars have conducted a lot of studies on the factors affecting the loosening of the bolted connection. Junker's research [7] indicates that dynamic tangential loads are more probable than axial loads to cause loosening, while he also proposed a simplified model of bolt looseness. Daadbin and Chow [8] also described a similar simplified model, but did not explore the relationship between the bolt loosening rate and the vibration frequency in the experiment. In this regard, Junker [7] established a kinematic model of bolted joints and explored the influence of high frequency vibration on bolt loosening, by numerical calculation. Their research found that bolt loosening may occur under dynamic excitation of certain frequencies and cyclic load. However, the frequency range they studied was significantly higher than the vibration frequency tolerance range of the structure in actual engineering. However, Housari [9] found that lower load frequency is more likely to cause the nut to rotate, meaning it can reduce the bolt preload more than the high frequency load, in the same number of load cycles, which was also experimentally verified. Later, Saurabh Biswas [10] found that, for a single bolted connection, the same hysteresis model can improve the bolted connection performance, within a certain range of friction coefficient and bolt pre-tightening force, slowing down bolt loosening. However, no specific range of friction coefficient was given. Dean Chen [11] also proposed that bolted connections with non-parallel contact surfaces can cause bolts to loosen.

In the study of the effects of lateral loads on the loosening of bolts, Zadoks and $\mathrm{Yu}$ [12] of the University of Texas believe that as long as the amplitude of the lateral load is large enough to cause tangential relative motion between fasteners, the bolted connection will loosen under cyclic loading. Sakai [13] conducted theoretical and experimental studies on bolt loosening caused by lateral loads and defined the minimum amount of sliding between the fasteners that would allow relative sliding of the threaded support surfaces. However, the actual impact of the lateral load on the bolted connection is complicated, while it can affect the frictional force provided at that point and in different contact directions. Later, Housari $[14,15]$ improved the model proposed by Sakai and derived the motion model of the bolt through the lateral load action history. The model takes into 
account the bending of the bolt, caused by the lateral excitation, the changes of the pressure and the friction generated between the contact surfaces, while it uses the method of fragmenting the contact surface to perform mechanical analysis, to finally splice into an overall response model. However, due to the complexity of the contact force distribution, the analytical process uses a linear assumption, so the model cannot reflect the relationship between the actual preload and the number of cycles. In 2006, Nassar [16] solved the contact stress, frictional moment, and shear stress between the threaded support surface and the contact thread under lateral load by establishing a mathematical model. Due to the complexity of the structure and stress of the thread, the model is simplified providing limited accuracy. In 2009, Nassar and Yang [17-20] solve the tangential force and friction moment at the support surface and the thread, under lateral cyclic load, through accurate mathematical modelling, while the looseness analysis criterion of the bolt structure is obtained. The conclusion has great reference value, but this model has also significantly simplified the actual situation, considering an extremely limited number of factors. In 2011, A.Talha [21] proposed that the preload and displacement have an important impact on the fretting-slip of the bolted connection, believing that micro-sliding becomes more obvious as the preload increases. T.N. Chakherlou and A.B. Aghdam [22] confirmed an increase in pre- tightening torque and an increase in fatigue life. However, the service time of a bolted assembly will not increase at a higher pre- tightening torque, which may cause the bolted connection to fail within a certain torque range. Also, Taha Benhaddou [23] used experimental and numerical approaches to propose that the axial preload has a beneficial effect on the service performance of conventional bolted connections.

Due to the close interaction between the working factors affecting the bolt looseness under vibration of machine tools, the main working factors affecting the bolt preload attenuation are difficult to study, while the law of bolt loosening is extremely difficult to define [24-27]. In the past, the experimental research on bolt looseness was mostly based on the influence principle of a single factor. Certain combinations of influence parameters were selected based on experimental data, which lacked systematic and scientific validation. The experimental results are not consistent with the actual looseness conditions $[28,29]$. Therefore, this study designs a comprehensive test plan, based on the quadratic general rotary unitized design method, taking into account the working factors affecting the bolt preload attenuation under vibration. The dynamic analysis of the bolted connection is carried out to interpret the generate of fretting slip and the reason for the loosening of bolts. During the cyclic action of alternating load, the effects of frequency, cyclic load, and pretightening torque on the bolt preload attenuation are deeply explored. The bolt preload attenuation after the test is analyzed, and then the quadratic regression mathematical model of the bolt clamping 
force attenuation is established. According to the statistical test and analysis of the model, the main working parameters are determined and the predicted value of the bolt preload attenuation rate is obtained by Particle Swarm optimization, which shows a high degree of coincidence with the respective experimental value. The research results provide an important experimental basis for improving the machining stiffness of machine tools, while they are very significant for the study of the loosening mechanism of the bolted connection in machine tools.

\section{Working factors affecting bolt looseness in machine tools under} vibration

Bolt loosening analysis in machine tools and prediction are both important and complex, while the impact on bolt clamping forces involves various external environmental factors, as well as their own factors. These factors include bolt preload $F_{b}$, working load $F(t)$ (cyclic load, frequency), working temperature $T$, structural form and the nominal bolt diameter $d_{i}$, structure material $m_{i}$, and contact surface state (coefficient of friction $\mu_{i}$ ) [30].

The main objective of the bolt looseness research is to study the evolution of the bolt preload in the specified service state. A mathematical model describing the loosening process of the bolted connection can be obtained as [31]:

$$
\frac{d F_{p}}{d_{t}}=f\left(F_{b}, F(t), T, d_{i}, m_{i}, \mu_{i}, \ldots\right)
$$

Although various factors have an important impact on the loosening process of bolted connection in machine tools, the working temperature, structure form and size, structural material, and surface state of the bolted structure are uncontrollable under vibration, while the dynamic external load is a necessary condition to affect the loosening of the bolted connection. In order to quantitatively study the characteristics of deterministic load, that is, cyclic load and load frequency, as well as the influence of bolt pre-tightening force on loosening, it is necessary to explore the influence of the factors one by one.

\section{Dynamic analysis of bolted connection in machine tools}

The definition of a mechanical model of tightening torque is necessary, in order to reveal the mechanism for bolt tightening torque attenuation in machine tools. Since the friction angle on the 
threaded contact surface of the bolted assembly in machine tools during tightening is generally greater than the helix angle of the thread, if the creep relaxation is not considered, the bolted connection in the static state after the preloading is unlikely to become loose. Therefore, the mathematical model of the pre-tightening torque $T_{f}$ can be obtained as [32]:

$$
T_{f}=\left(\frac{P}{2 \pi}+1.155 \mu_{t} r_{t}+\mu_{b} r_{b}\right) \cdot F_{b}
$$

where, $P$ is the pitch of threads, $\mu_{t}$ is the friction coefficient of the contact surface between the external thread of the bolt and the internal thread of the nut, $r_{t}$ is the pitch radius of the bolt, $\mu_{b}$ is the friction coefficient between the lower surface of the nut and the bearing surface of the joint member, while $r_{b}$ is the effective radius of the nut surface.

\subsection{Bolted connection sample in in machine tools}

In order to investigate the effect of vibration on bolt preload attenuation of the bolted connection in machine tools, a connection structure that is commonly used in machine tools was designed to perform bolt looseness tests. As shown in Fig. 1, the bolt loosening experiment was carried out on the designed specimen. The design of the sample meets the requirements of the INSTRON 8801 testing machine, which is used for the loosening experiments.

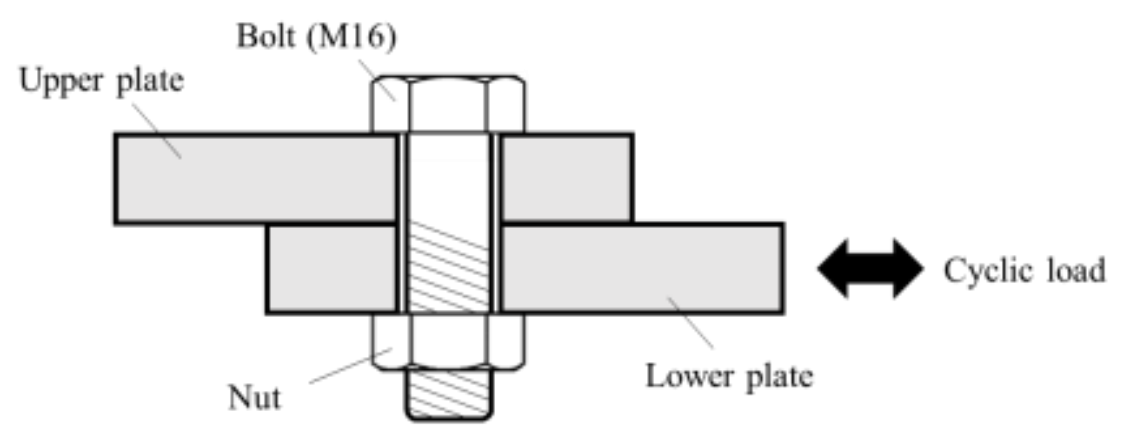

Fig. 1 Bolted test sample

Hexagon bolts of strength grade 8.8 with M16×80 nuts were used in the loosening tests. During the nut tightening process, the nut is lowered $1 \mathrm{~mm}$ above the contact surface, while then a digital torque wrench is used, to achieve the torque load required for the test [33]. The same tightening operation is performed on each test sample, to ensure that the same torque load is applied on the nut.

\subsection{Effect of deterministic load on the characteristics of the bolted connection}

The research object shown in Fig. 1 is used to explore the influence of deterministic load on the characteristics of the bolted connection in machine tools. First, the finite element model of the bolted 
connection is established, while the deterministic load is applied to the bolt connection after pretightening for simulation calculation. Croccolo $[34,35]$ assumed that the friction coefficient of the threaded joint friction interface would change during pre-tightening. The threaded connection is used in the finite element model because the friction coefficient of the contact surface needs to be considered, when the nut is pre-tightened. The finite element mesh of each component and assembly is shown in Fig. 2. Taking into account the calculation accuracy and efficiency, the threaded connection and the overlapping area of the connecting plate where slippage occurs are finely meshed. The hexagonal shape of the bolt head and nut is simplified into a circle, the same as in previous work [36].

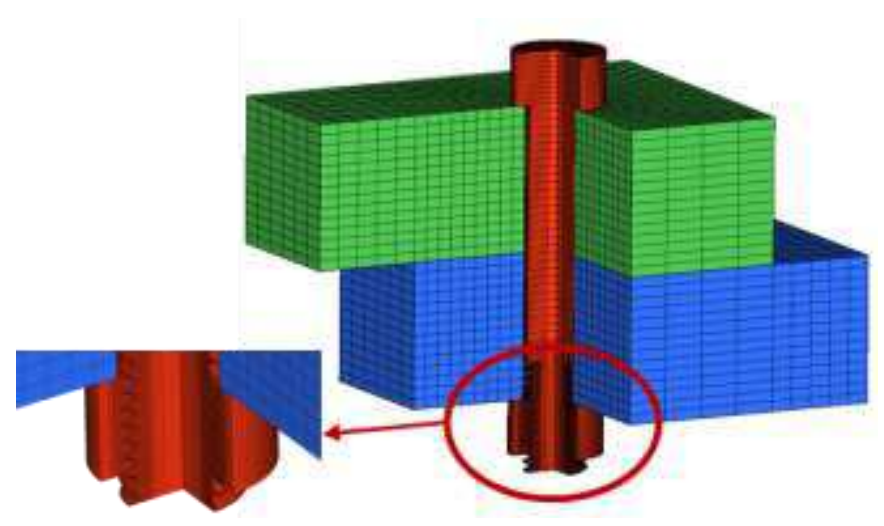

(a) Meshing of FE model

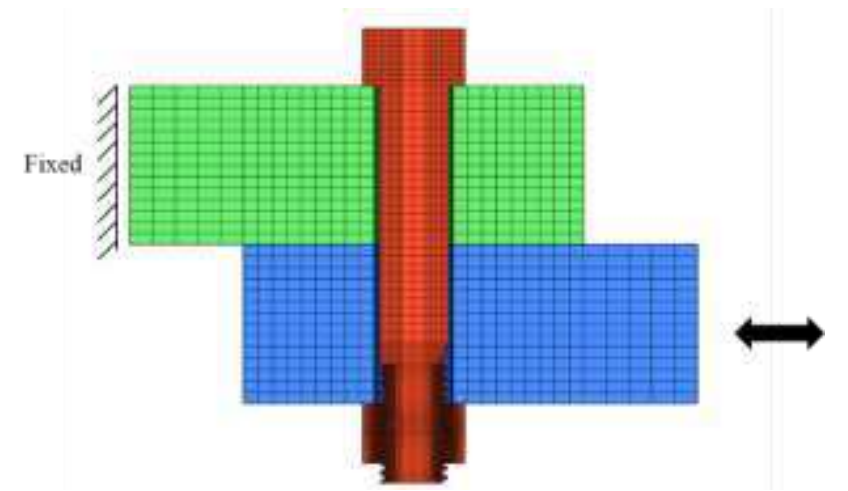

(b) Boundary condition

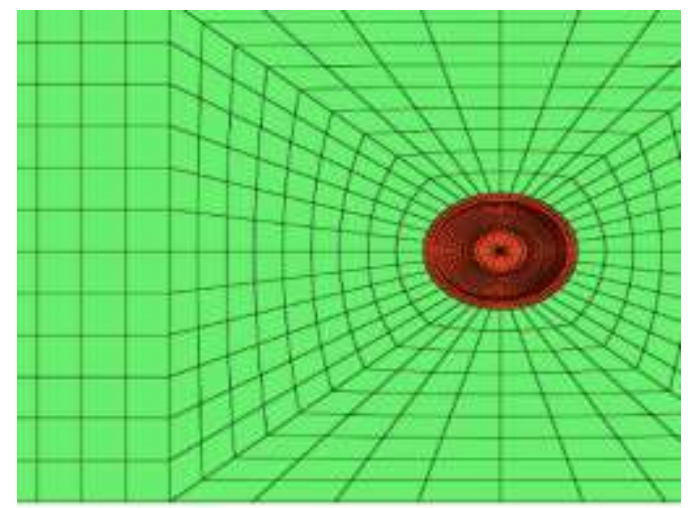

(c) Contact surface 
Fig. 2 Numerical model.

The material characteristics of the bolt connection are listed in Table 1.

Table 1. Material properties of bolts and connected parts

\begin{tabular}{ccccc}
\hline Components & Density & Elastic Modulus & Yield Strength & Poisson's ratio v \\
& $\rho\left(t \cdot \mathrm{mm}^{-3}\right)$ & $E(G P a)$ & $R_{e}(\mathrm{MPa})$ & \\
\hline Bolt/Nut & $7.85 \times 10^{-9}$ & 209 & 640 & 0.32 \\
\hline Upper plate & $7.8 \times 10^{-9}$ & 206 & 640 & 0.3 \\
\hline Lower plate & $7.8 \times 10^{-9}$ & 206 & 640 & 0.3 \\
\hline
\end{tabular}

Figure 3 illustrates the interface pressure distribution diagram when a tightening torque of 50 $\mathrm{nm}$ is applied to the nut. In the bolt connection model after pre-tensioning, the stress concentration area appears at the first few turns of the thread, indicating that the screw and the nut are completely matched.

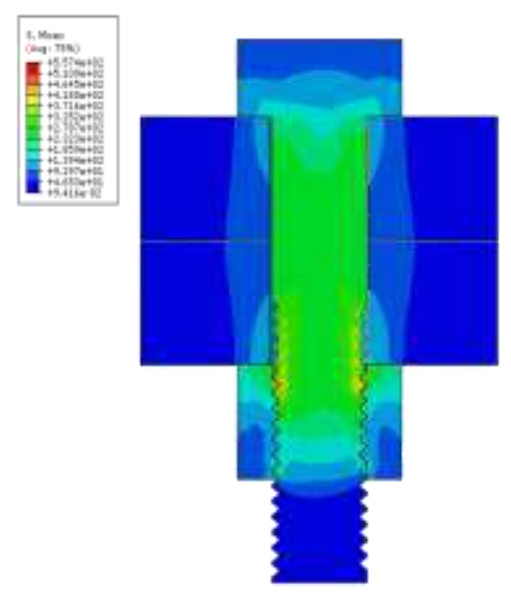

Fig. 3 Stress distribution on bolted connection

The boundary conditions are applied to the model, where the left end of the connection is completely fixed, while the right end only retains the tangential displacement degrees of freedom. As shown in Fig. 4, the changes in the dynamic characteristics of the bolt connection are observed by applying a deterministic load to the right end of the model, where the cyclic load is $5 \mathrm{KN}$ and the load frequency is $6 \mathrm{~Hz}$. 


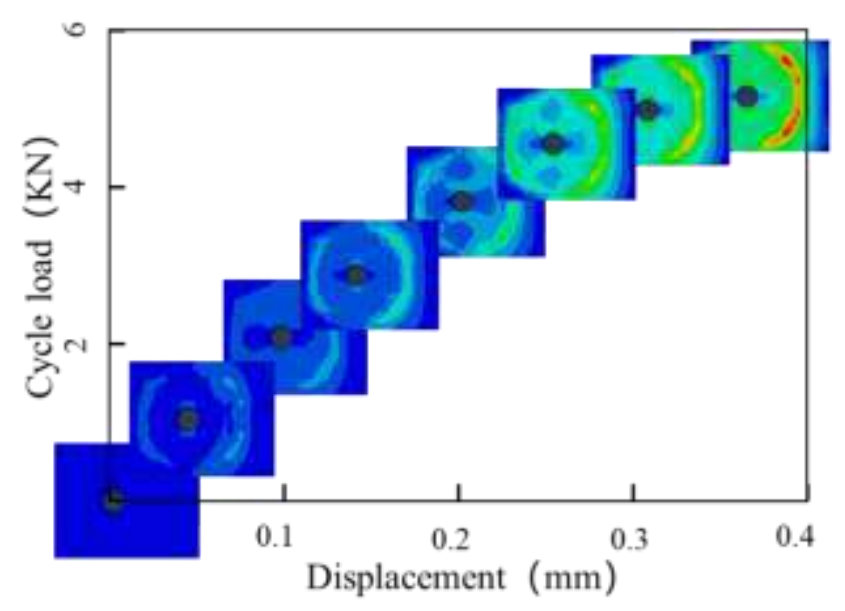

Fig. 4 Evolution of fretting slip on the joint surface

Under tangential cyclic loading, the contact surface of the bolt connection will gradually transit from the initial mutual adhesion state to the fretting slip state. The results show that, as the load increases, the sliding area of the interface gradually grows, while the adhesion area gradually decreases. The color of the green area gradually becomes brighter, which indicates that the bolt connection has fretting slip, whereas red gradually appears in the middle, indicating stress concentration appears between the interfaces and fretting wear should appear on the surface, reducing the bolt clamping force. Therefore, it is deduced that the deterministic load will affect the dynamic performance of the bolt connection and eventually cause the bolt looseness to degenerate the machining stiffness of machine tools.

\section{Experimental Test}

Exploring the bolt preload attenuation law in machine tools is very important to studying the degradation of machining stiffness. Finding the influence of various factors on the bolt preload attenuation is the primary goal in the study of bolt looseness. According to the analysis results, the working parameters that need to be considered, as affecting the looseness of the bolted connection under vibrating behavior, are the pre-tightening torque, the cyclic load and the load frequency.

\subsection{Design of working factors via quadratic general rotating combination technique}

The three factors of different impact levels are listed in Table 2. Here, $x_{j}$ is the coded formula, $T_{0}$ represents the pre-tightening torque, $F_{t}$ is the cyclic load, and $f$ is the load frequency. All were divided into five levels with codes set as: $\pm r, \pm 1,0$. 
Table 2 Three working factors level code table

\begin{tabular}{cccc}
\hline$Z_{j}\left(x_{j}\right)$ & $Z_{1}\left(T_{0} / N \cdot m\right)$ & $Z_{2}\left(F_{t} / \mathrm{KN}\right)$ & $Z_{3}(f / \mathrm{Hz})$ \\
\hline$Z_{2 j}(r)$ & 85.23 & 5.682 & 7.523 \\
$Z_{0 j}+\Delta_{j}(1)$ & 75 & 5 & 6.5 \\
$Z_{0 j}(0)$ & 60 & 4 & 5 \\
$Z_{0 j}-\Delta_{j}(-1)$ & 45 & 3 & 3.5 \\
$Z_{1 j}(-r)$ & 34.77 & 2.318 & 2.477 \\
$\Delta_{j}=\left(Z_{j}-Z_{0 j}\right) / x_{j}$ & 15 & 1 & 1.5 \\
\hline
\end{tabular}

The target results of 20 samples were obtained via a conventional cyclic load test method, where the pre-tightening torque, cyclic load and load frequency took on varying values. The 8.8 class bolts used in the loosening test were M16 $\times 80$, while for the rest of the specifications, such as size specifications and certification, one may refer to [37]. As shown in Fig. 5, in order to remove the contaminants remaining from the manufacturing process, the bolts and contact surfaces were cleaned with ethanol before each set of experiments. The pre-tightening torque was applied to the bolted joint to ensure complete contact between the test bolt and the connector before the experiment If the bolt preload does not reach the specified range, the nut is replaced.

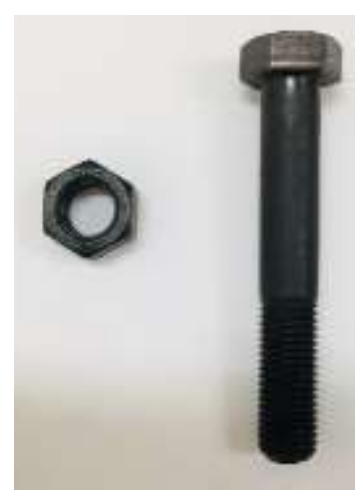

(a) Single bolt and nut

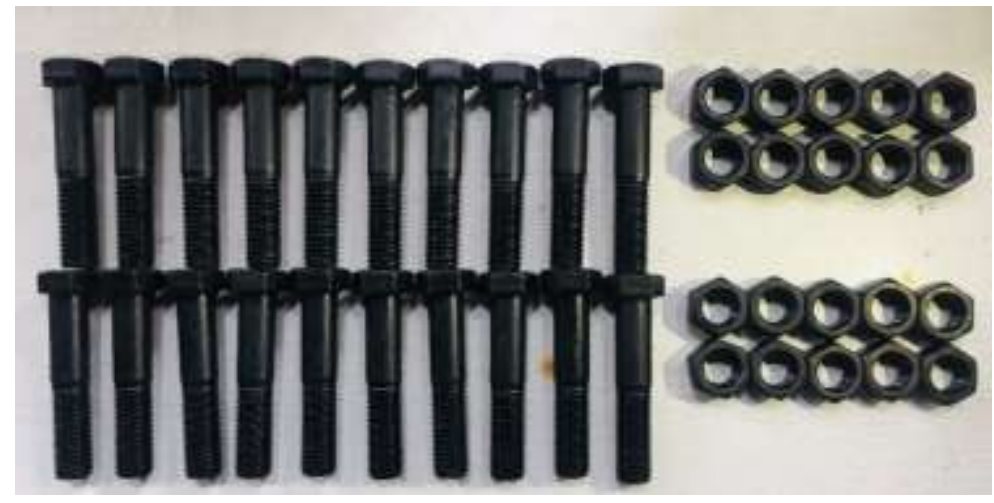

(b) 20 sets of bolts and nuts

Fig. 5 Bolts and nuts after treatment

\subsection{Characterization of experimental results}

During the test, in order to record the change of the bolt preload accurately in real time, the bolt looseness experimental model was established as shown in Fig. 6. The model mainly includes the vibration system, the control system, the data acquisition system, and the processing system. The 
vibration system equipment is the INSTRON8801 tensile testing machine. The control system equipment is mainly the tensile testing machine controller. The test parameters are controlled by a setting program. The data acquisition system equipment includes pressure sensor, signal amplifier and data acquisition card. The data processing system converts the acquired pressure signal into clamping force.

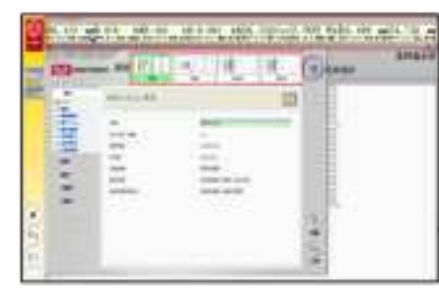

Experimental system control program

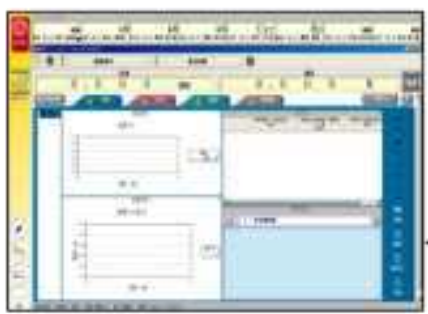

Dynamic experimental test program

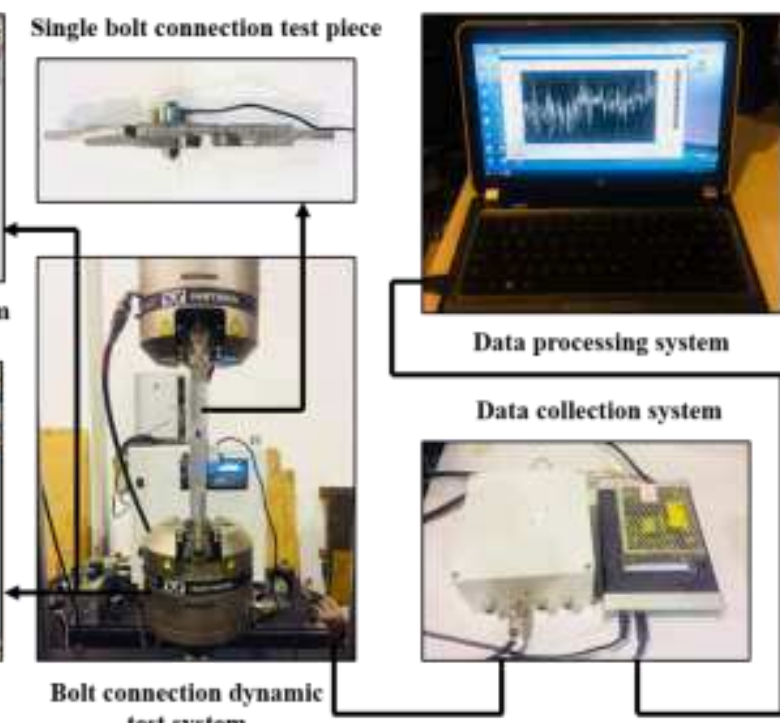

test system

Fig. 6- Bolt relaxation test connecting device

Data acquisition was performed using the SMACQ acquisition card for the clamping force obtained under each combination of test parameters and monitored in real time. Each set of test pieces was subjected to $14.4 \times 10^{3}$ cycles of testing, while the acquired data was post-processed. The bolt preload attenuation rate $\varphi$ can be defined as:

$$
\varphi=\left(\frac{F_{b}-F_{1}}{F_{b}}\right) \times 100
$$

where, $F_{b}$ is the bolt preload, as obtained by the pre-tightening torque, $F_{1}$ is the difference between the bolt preload obtained from the pre-tightening torque and the final bolt clamping force measured by the pressure sensor.

\section{Results and discussion}

\subsection{Experimental results}

According to the work level code table shown in Table 2, based on the quadratic general rotary unitized design (QGRUD) method, 20 samples were tested about bolt looseness, where various pretightening torque, cyclic load and load frequency were applied. As shown in Table 3, the attenuation 
rate of the bolt preload was calculated based on the experimental results of each set.

Table 3 Three-factor experiment results based on QGRUD method

\begin{tabular}{cccccccc}
\hline No. & $x_{1}$ & $x_{2}$ & $x_{3}$ & $Z_{1}$ & $Z_{2}$ & $Z_{3}$ & $Y(\%)$ \\
\hline 1 & 1 & 1 & 1 & 75 & 5 & 6.5 & 9.6 \\
2 & 1 & 1 & -1 & 75 & 5 & 3.5 & 8.8 \\
3 & 1 & -1 & 1 & 75 & 3 & 6.5 & 6.8 \\
4 & 1 & -1 & -1 & 75 & 3 & 3.5 & 6.0 \\
5 & -1 & 1 & 1 & 45 & 5 & 6.5 & 11.5 \\
6 & -1 & 1 & -1 & 45 & 5 & 3.5 & 10.3 \\
7 & -1 & -1 & 1 & 45 & 3 & 6.5 & 8.1 \\
8 & -1 & -1 & -1 & 45 & 3 & 3.5 & 7.3 \\
9 & -1.682 & 0 & 0 & 34.77 & 4 & 5 & 9.9 \\
10 & 1.682 & 0 & 0 & 85.23 & 4 & 5 & 7.1 \\
11 & 0 & -1.682 & 0 & 60 & 2.318 & 5 & 5.8 \\
12 & 0 & 1.682 & 0 & 60 & 5.682 & 5 & 15.1 \\
13 & 0 & 0 & -1.682 & 60 & 4 & 2.477 & 6.8 \\
14 & 0 & 0 & 1.682 & 60 & 4 & 7.523 & 10.3 \\
15 & 0 & 0 & 0 & 60 & 4 & 5 & 8.8 \\
16 & 0 & 0 & 0 & 60 & 4 & 5 & 9.1 \\
17 & 0 & 0 & 0 & 60 & 4 & 5 & 7.9 \\
18 & 0 & 0 & 0 & 60 & 4 & 5 & 8.7 \\
19 & 0 & 0 & 0 & 60 & 4 & 5 & 8.3 \\
20 & 0 & 0 & 0 & 60 & 4 & 5 & 7.5 \\
\hline & & & & & & &
\end{tabular}

\subsection{Establishment of analytical model}

Under the excitation of the fatigue tensile tester, the attenuation rate of the bolt preload in each test set is calculated under the same conditions. The QGRUD method was used to investigate the pre-tightening torque, cyclic load and load frequency effects on bolt preload attenuation rate in order to obtain the results of bolt preload variations. According to the aforementioned bolt preload attenuation rate, the regression coefficients $b_{0}, b_{j}, b_{i j}$, and $b_{j j}$ of the analytical model were obtained as [27]: 


$$
\left\{\begin{array}{l}
b_{0}=K \sum_{\alpha} y_{\alpha}+E \cdot \sum_{j=1}^{m}\left(\sum_{\alpha} x_{\alpha j}^{2} y_{\alpha}\right) \cdot \alpha \\
b_{j}=e^{-1} \sum_{\alpha} x_{\alpha j} y_{\alpha} \\
b_{i j}=m_{c}^{-1} \sum_{i<j}^{\alpha}\left(x_{\alpha i} x_{\alpha j}\right) \cdot y_{\alpha} \\
b_{j j}=(F-G) \sum_{\alpha} x_{\alpha j}^{2} y_{\alpha}+G \cdot \sum_{j=1}^{m} x_{\alpha j}^{2} y_{\alpha}+E \cdot \sum_{\alpha} y_{\alpha}
\end{array}\right.
$$

where, $K, E, \alpha, F, G, m_{c}$ and $m$ are all process parameters [27], $x$ represents the level code, and $y$ is the bolt preload attenuation rate. Next, the necessary parameters can be obtained as:

$$
\left\{\begin{array}{l}
E=-2 H^{-1} e \gamma^{4} \\
F=H^{-1}\left[N f+(m-2) N m_{c}-(m-1) e^{2}\right] \\
G=H^{-1}\left(e^{2}-N m_{c}\right) \\
K=2 \gamma^{4} H^{-1}\left[f+(m-1) m_{c}\right] \\
e=m_{c}+2 \gamma^{2} \\
f=m_{c}+2 \gamma^{4} \\
H=2 \gamma^{4}\left[N f+(m-1) N m_{c}-m e^{2}\right]
\end{array}\right.
$$

According to Eq. (4), Eq. (5) and the data of the bolt clamping force attenuation rate listed in Table 3, the analytical model can be obtained as:

$$
\begin{aligned}
& Y=8.40478-0.78415 x_{1}+2.02394 x_{2}+0.69462 x_{3}-0.09891 x_{1}^{2} \\
& +0.59052 x_{2}^{2}-0.08123 x_{3}^{2}-0.1 x_{1} x_{2}-0.05 x_{1} x_{3}+0.05 x_{2} x_{3}
\end{aligned}
$$

where, $x_{1}, x_{2}$, and $x_{3}$ represent the coding space values of pre-tightening torque, cyclic load, and load frequency, respectively.

\subsection{Model validation}

In order to determine the authenticity and reliability of Eq. (6), it is necessary to check and test the prediction model in Eq. (6). The regression of the prediction model can be tested by $F$-test method, while the regression coefficient can be tested by t-test method [27]. Therefore, sum of deviation squares $\left(S_{o}, S_{R}, S_{L}, S_{E}\right)$ and degree of freedom $\left(D_{o}, D_{R}, D_{L}, D_{E}\right)$ are calculated and listed in Table 4.

Table 4 Variance analysis of bolt preload attenuation

\begin{tabular}{cccc}
\hline Source of variance & Sum of squares & Degree of freedom & Mean \\
\hline Orthogonal & $76.6682\left(S_{o}\right)$ & $9\left(D_{o}\right)$ & 8.5187 \\
Residual & $9.7173\left(S_{R}\right)$ & $10\left(D_{R}\right)$ & 0.9717 \\
Loss of fit & $7.9090\left(S_{L}\right)$ & $5\left(D_{L}\right)$ & 1.5818 \\
\hline
\end{tabular}




\begin{tabular}{cccc}
\hline Error & $1.8083\left(S_{E}\right)$ & $5\left(D_{E}\right)$ & 0.3617 \\
Sum & 86.3855 & 19 & - \\
\hline
\end{tabular}

Numerical analysis tests are carried out, based on the above analysis results, then the tested result $F_{1}$ can be obtained as:

$$
F_{1}=\frac{S_{L} / D_{L}}{S_{E} / D_{E}}=4.374<F_{0.01}(5,5)=10.97
$$

The calculation result is within the experimental error range, so the established model is proven suitable for prediction. Then, the regression test result $F_{2}$ can be obtained as:

$$
F_{2}=\frac{S_{o} / D_{o}}{S_{R} / D_{R}}=8.767>F_{0.01}(9,10)=4.94
$$

It is indicated that the significance level of this regression equation is 0.01 , the influence of the three dependent variables (the pre-tightening torque, the cyclic load and the load frequency) on the bolt preload attenuation rate is highly significant, while the confidence of the regression equation is at $99 \%$.

Considering that the estimation of the regression model is based on the assumption that the model residual obeys the normal distribution, if the residual does not obey the normal distribution, then all the estimation analyses performed on the regression model are unreliable. The DurbinWatson statistic is used to test whether the residual distribution is a normal distribution which can be expressed as:

$$
D W=\frac{\sum_{i=2}^{T}\left(\hat{\varepsilon}_{i}-\hat{\varepsilon}_{i-1}\right)^{2}}{\sum_{i=1}^{T} \hat{\varepsilon}_{i}^{2}}
$$

where, $\hat{\varepsilon}_{i}$ is variance in the regression equation.

According to the number of samples and the number of factors, it can be seen from the DW distribution test that $1.676<\mathrm{DW}=1.915<2.324$. The residual scatter distribution is shown in Fig. 7 , where it is evident that model residuals do not have autocorrelation. Therefore, the residual of this regression equation follows the normal distribution. Hence, the assumption is true and the regression equation is reliable. 


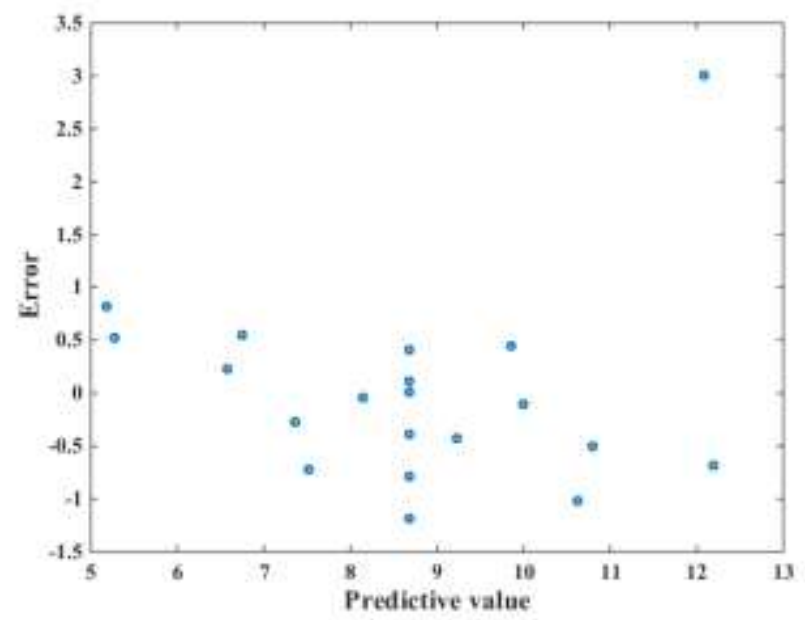

Fig. 7 Residual scatter plot of bolt preload attenuation rate

The experimental results show that the significance levels of all regression coefficients are different. Therefore, the mathematical model can predict and optimize the bolt preload attenuation rate.

As shown in Table 5, the P-values of $x_{2}$ (cyclic load) were $<0.01$, in the single-factor analysis procedure, which shows that $x_{2}$ has the greatest influence on the bolt preload attenuation rate. The effect of working factors on bolt preload attenuation rate could be observed via the range and change tendency of each factor in the analysis of single factor effect. The result showed that $x_{2}$ mainly influenced the bolt preload attenuation rate (Y-value) while $x_{1}$ (Pre-tightening torque) and $x_{3}$ (Load frequency) are of less influence.

Table 5 The analysis of variance table for different working factors

\begin{tabular}{ccccccc}
\hline Variable & $\begin{array}{c}\text { Sum of } \\
\text { square }\end{array}$ & $\begin{array}{c}\text { Degree of } \\
\text { freedom }\end{array}$ & $\begin{array}{c}\text { Mean } \\
\text { square }\end{array}$ & $\begin{array}{c}\text { Partial } \\
\text { variance }\end{array}$ & F-value & P-value \\
\hline$x_{1}$ & 8.3975 & 1 & 8.3975 & -0.6809 & 8.6418 & 0.0148 \\
$x_{2}$ & 55.9431 & 1 & 55.9431 & 0.9230 & 57.5705 & 0.0001 \\
$x_{3}$ & 6.5893 & 1 & 6.5893 & 0.6357 & 6.7810 & 0.0263 \\
$x_{1}^{2}$ & 0.1410 & 1 & 0.1410 & -0.1196 & 0.1451 & 0.7112 \\
$x_{2}^{2}$ & 5.0254 & 1 & 5.0254 & 0.5838 & 5.1716 & 0.0462 \\
$x_{3}^{2}$ & 0.0951 & 1 & 0.0951 & -0.0984 & 0.0979 & 0.7608 \\
$x_{1} x_{2}$ & 0.0800 & 1 & 0.0800 & -0.0904 & 0.0823 & 0.7800 \\
$x_{1} x_{3}$ & 0.0200 & 1 & 0.0200 & -0.0453 & 0.0206 & 0.8887 \\
$x_{2} x_{3}$ & 0.0200 & 1 & 0.0200 & 0.0453 & 0.0206 & 0.8888 \\
\hline
\end{tabular}

Based on the range result, Fig. 8 shows that the influence on the bolt preload attenuation rate 
followed this order: $x_{2}$ (Cyclic load) $>x_{1}$ (Pre-tightening torque $)>x_{3}$ (Load frequency), which is consistent with the P-value of the analysis. This result verifies the different effect of the three working factors on the bolt preload attenuation rate.

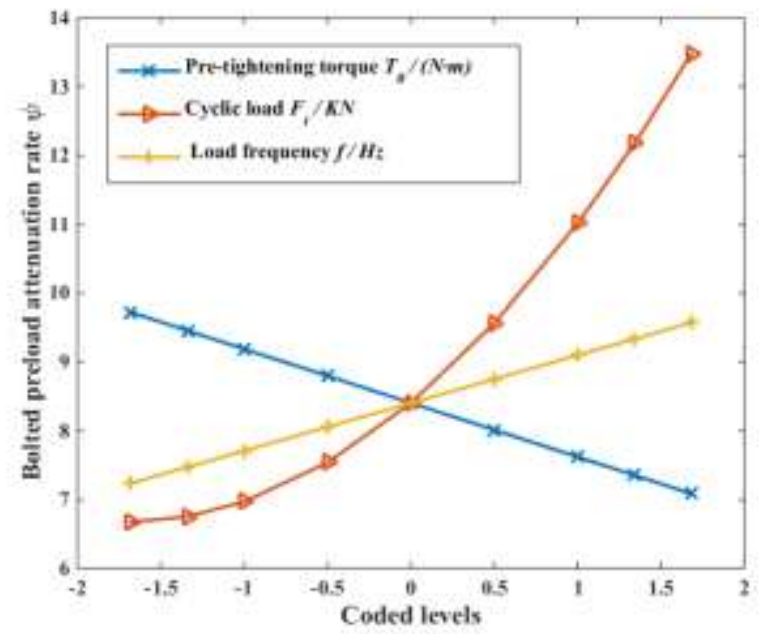

Fig. 8 Residual spot diagram of bolt preload attenuation rate

According to the results of the bolted connection test, a single factor often cannot fully explain the entire situation of the relaxation test, which requires additional analysis of the interaction effect of the factors. The interactive relationship effect of each influencing factor on the bolt preload attenuation rate is shown in Fig. 9. The $\mathrm{X}$ and $\mathrm{Y}$ axes are the horizontal coding values of the initial tightening torque and load amplitude, respectively, while the $\mathrm{Z}$ axis is the bolt preload attenuation rate.

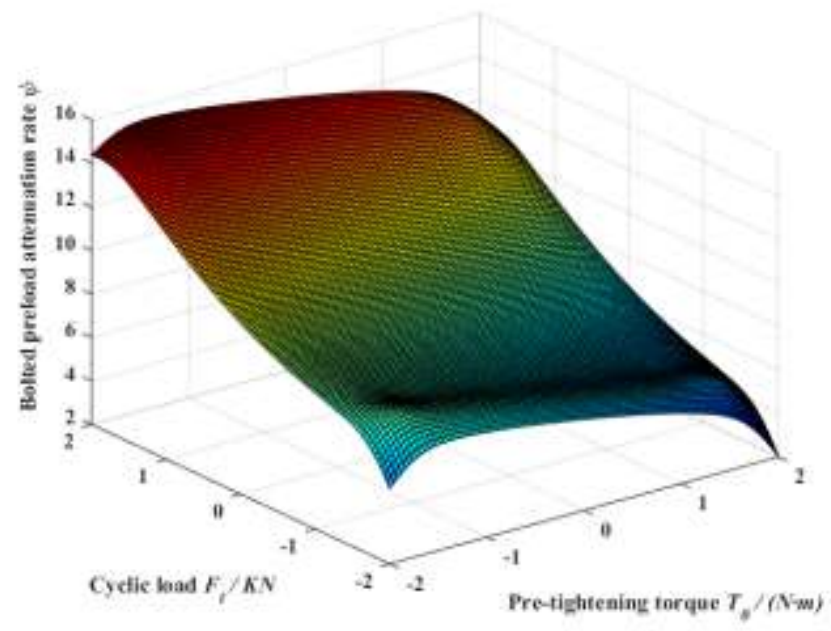

(a) The interaction of $x_{1}$ and $x_{2}$ on the bolt preload attenuation rate 


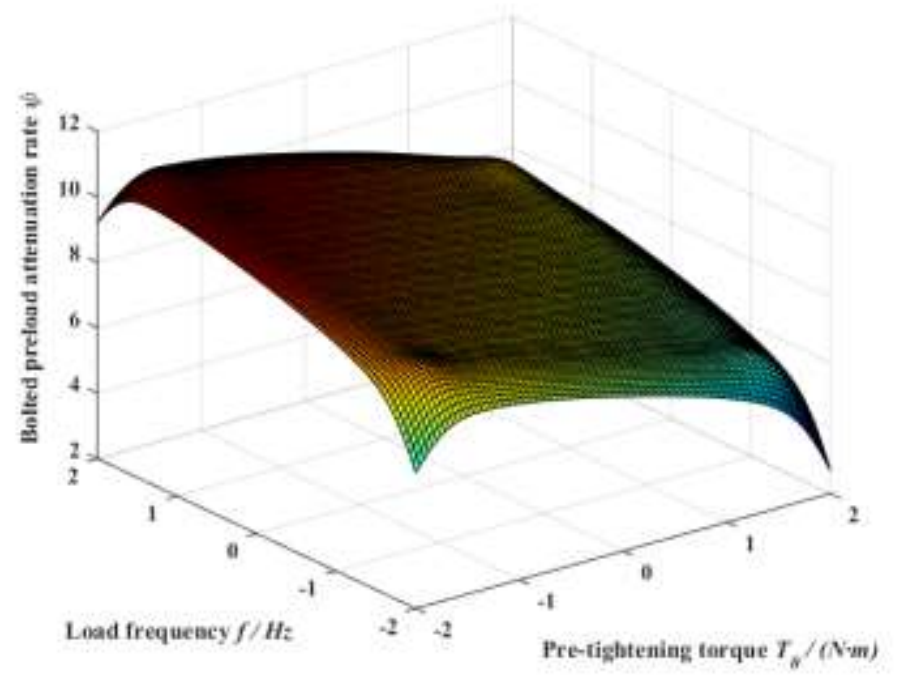

(b) The interaction of $x_{1}$ and $x_{3}$ on the bolt preload attenuation rate

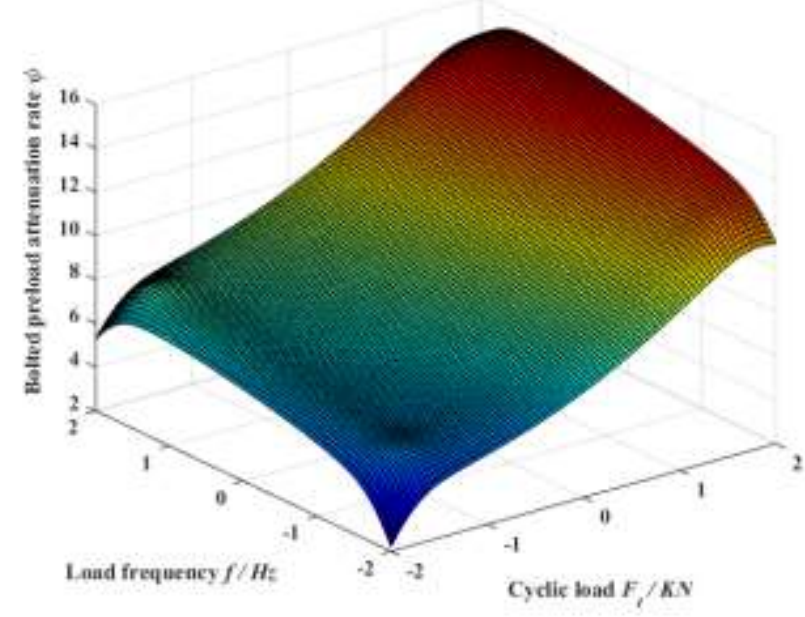

(c) The interaction of $x_{2}$ and $x_{3}$ on the bolt preload attenuation rate

Fig. 9 Interaction of different working factors on the bolt preload attenuation rate.

As shown in Fig. 9, when the initial tightening torque increases, the amplitude rises and the clamping force attenuation becomes more obvious. When the amplitude decreases, the higher the initial tightening torque, the smaller the bolt clamping force attenuation amplitude, while the bolt clamping force attenuation rate reaches the global minimum when the initial tightening torque is at its highest and the amplitude is minimum. The test analysis results are in line with actual working conditions. The results can be used to guide the secondary tightening of bolt connections to improve the overall stiffness of the machine tool. 


\subsection{Optimization of the analytical model}

Based on the obtained test results, the pre-tightening torque, the cyclic load, and the load frequency are variables, and the necessary constraints for the dynamic process of the bolt connection are added. On the premise of ensuring complete connection after bolt pre-tensioning, the lowest attenuation rate of the bolt preload is taken as the optimization goal, and the obtained analytical model is optimized based on the particle swarm optimization (PSO). The particle swarm optimization PSO is a heuristic algorithm, which has simple rules and is easy to implement. In addition, PSO has a fast convergence rate and is widely used in engineering. In addition, PSO has a strong global search capability, so it is very suitable for parameter optimization of the analytical model.

The analysis model is optimized to obtain the lowest bolt preload attenuation rate, corresponding to the pre-tightening torque of $85.23 \mathrm{~N} \cdot \mathrm{m}$, cyclic load of $2.5 \mathrm{KN}$ and load frequency at $2.477 \mathrm{~Hz}$. Then, in order to verify the effectiveness of the algorithm, the bolt loosening experiment was carried out based on the obtained optimal working factors of the same kind of specimen. The results show that the optimized value and the experimental value are 4.22 and 4.51 , respectively, while the prediction error is $6.4 \%$. It can be found that under the optimal working factors, the bolt preload attenuation rate is significantly reduced when the bolt connection is subjected to an external cyclic load.

\section{Conclusion}

In this paper, the dynamic performance of the bolted connection is analyzed through numerical simulation to determine the reason for the bolt looseness in machine tools. The quadratic general rotary unitized design method is used to perform an alternating load cyclic vibration test on the same batch of bolted connections, as based on the theory of rotational regression design. The vibration response of the bolted connection in machine tools, under the influence of different working factors, was studied. Based on the results of this study, the following conclusions can be drawn:

(1) Based on the numerical simulation results, the deterministic cyclic load will cause fretting slip between the bolt connections and the bolts to loosen.

(2) Based on the experimental results, the bolt preload attenuation rate decreases as the pretightening torque increases, while it increases as the cyclic load and load frequency rise.

(3) Based on the experimental results, the bolt preload attenuation was analyzed, while the quadratic regression mathematical model of bolt preload attenuation was established. According to 
the statistical test and analysis of the model, the principal working parameter affecting the bolt preload attenuation under vibration is the cyclic load.

(4) The optimal working factor under the lowest bolt preload attenuation rate is obtained based on the PSO algorithm, and the effectiveness of the algorithm is verified through experiments.

\section{DECLARATIONS}

\section{Ethical Approval}

Not applicable.

\section{Consent to Participate}

Not applicable.

\section{Consent to Publish}

Not applicable.

\section{Authors Contributions}

Qiang Cheng is responsible for providing overall research ideas, Wenxiang $\mathrm{Xu}$ is responsible for the dynamic experimental design of bolted connections, Congbin Yang is responsible for experimental data analysis, and Ying $\mathrm{Li}$ is responsible for the operation of experimental instruments.

\section{Funding}

This research is supported by the National Natural Science Foundation of China (No. 51975019) and Beijing Nova Programme Interdisciplinary Cooperation Project (No. Z191100001119010).

\section{Conflicts of interest}

There are no conflicts of interest.

\section{Availability of data and materials}

Not applicable.

\section{References}

[1] Guo, T. , et al. "Alternative method for identification of the dynamic properties of bolted joints." Journal of Mechanical Science and Technology 26.10(2012).

[2] Gao, X. , et al. "Stiffness modeling of machine tools based on machining space analysis." International Journal of Advanced Manufacturing Technology 86(2016):1-14.

[3] Ren, S. L. , et al. "The Modeling Methods of Heavy NC Machine Tool Bolt Joint Based on Virtual Media." International Journal of Smart Home 9.9(2015):29-36.

[4] Jiang Y, Zhang M, Park T W, et al. An Experimental Study of Self-Loosening of Bolted Joints. Journal of Mechanical Design 2004; 126:925. 
[5] Caccese V, Berube K A, Fernandez M, et al. Influence of stress relaxation on clamp-up force in hybrid composite-to-metal bolted joints. Composite Structures 2009; 89:285-293.

[6] Zhang X, Yu H P, Su H, et al. Experimental evaluation on mechanical properties of a riveted structure with electromagnetic riveting. International Journal of Advanced Manufacturing Technology, 2016, 83(9-12):2071-2082.

[7] JUNKER, Gerhard H. Criteria for self loosening of fasteners under vibration. Aircraft Engineering and Aerospace Technology 1972; 44:14-16.

[8] Daadbin A, Chow Y M. A theoretical model to study thread loosening. Mechanism and Machine Theory 1992; 27:69-74.

[9] Housari, Basil A, Nassar, Sayed A. Effect of Thread and Bearing Friction Coefficients on the Vibration-Induced Loosening of Threaded Fasteners. Journal of Vibration and Acoustics 2007; 129: 484. doi:10.1115/1.2748473.

[10] Biswas S, Chatterjee A. A two-state hysteresis model for bolted joints, with minor loops from partial unloading[J]. International Journal of Mechanical Sciences 2018; S0020740317320775.

[11] Dean, Chen, Y. Ma. Tightening behavior of bolted joint with non-parallel bearing surface. International Journal of Mechanical Sciences 2019.

[12] Zadoks R I, Yu X. An investigation of the self-loosening behavior of bolts under transverse vibration. Journal of Sound \& Vibration 1997; 208:189-209.

[13] SAKAI, Tomotugu. Investigations of Bolt Loosening Mechanisms : 1st Report, On the Bolts of Transversely Loaded Joints. Bulletin of JSME 1978; 21(159):1385-1390.

[14] Nassar S A, Housari B A. Study of the Effect of Hole Clearance and Thread Fit on the SelfLoosening of Threaded Fasteners. Journal of Mechanical Design 2007; 129:586.

[15] Housari B A, Nassar S. A. Effect of Coating and Lubrication on the Vibration-Induced Loosening of Threaded Fasteners. Design Engineering and Computers and Information in Engineering, Parts A and B 2006; doi:10.1115/imece2006-16185

[16] Sayed, A, Nassar, et al. Effect of Thread Pitch and Initial Tension on the Self-Loosening of Threaded Fasteners. Journal of Pressure Vessel Technology 2005.

[17] Nassar, Sayed A, Yang, Xianjie. Torque-Angle Formulation of Threaded Fastener Tightening. Journal of Mechanical Design 2008; 130(2):024501.

[18] Nassar S A, Yang, X. A mathematical model for vibration-induced loosening of preloaded threaded fasteners. Journal of Vibration and Acoustics 2009; 131: 557-557.

[19] Yang, X, Nassar, S. Analytical and Experimental Investigation of Self-Loosening of Preloaded Cap Screw Fasteners. Journal of Vibration and Acoustics 2001; 133: 031007. 
[20] Yang, X, Nassar, S. A, Wu, Z. Criterion for Preventing Self-Loosening of Preloaded Cap Screws Under Transverse Cyclic Excitation. Journal of Vibration and Acoustics 2011; 133: 041013.

[21] Benhamena A, Talha A, Benseddiq N, et al. Effect of clamping force on fretting fatigue behaviour of bolted assemblies: Case of couple steel-aluminium. Materials Science \& Engineering: A (Structural Materials: Properties, Microstructure and Processing) 2010; 527:6413-6421.

[22] Chakherlou T N, Razavi M J, Aghdam A B , et al. An experimental investigation of the bolt clamping force and friction effect on the fatigue behavior of aluminum alloy 2024-T3 double shear lap joint. Materials \& Design 2011; 32:4641-4649.

[23] Benhaddou T, Stephan P, Daidie A, et al. Effect of axial preload on durability of aerospace fastened joints. International Journal of Mechanical Sciences 2018; 137:214-223.

[24] Li, Ming Y. Optimization Study on FRP Bolt-End Structure Parameters. Advanced Materials Research 2011; 295-297:2438-2441.

[25] Zhengwei C, Shudong L, Wanming G, et al. Experiment research on bolted connection assembly failure for metro vehicle. Modern Manufacturing Engineering 2017.

[26] Wang Q, Zhou X J, Liu Z L, et al. Performance Analysis and Optimization of Flange Bolt Joint under the Influence of Inhomogeneous Temperature Field. Applied Mechanics and Materials 2011; 121-126:1656-1662.

[27] Yin G F, L, Mi, et al. Optimization Method of Machining Center Multi-joint Stiffness Based on Orthogonal Experiment and FEA. Materials Science Forum 2012.

[28] L.Q. Ren, Regression Design and Optimization, First ed., Science Press, Beijing 2009.

[29] Q.Y. Tan, DPS data processing system, First ed., Science Press, Beijing 2009.

[30] Berthier Y, Vincent L, Godet M. Fretting fatigue and fretting wear 1989; 22:235-242.

[31] Izumi S, Yokoyama T, Iwasaki A, et al. Three-dimensional finite element analysis of tightening and loosening mechanism of threaded fastener. Engineering Failure Analysis 2005; 12:604-615.

[32] Li H, Tian W, Meng Y, Chen K. Experimental study of the loosening of threaded fasteners with transverse vibration. Journal of Tsinghua University (Natural Science) 2016; 2:171-175.

[33] José María Mínguez, Vogwell J. Effect of torque tightening on the fatigue strength of bolted joints. Engineering Failure Analysis 2006, 13:1410-1421.

[34] Croccolo D, Agostinis M D, Vincenzi N. Failure analysis of bolted joints: Effect of friction coefficients in torque-preloading relationship. Engineering Failure Analysis 2011; 18:364-373.

[35] Croccolo D, Agostinis M D, Nicolò Vincenzi. Influence of tightening procedures and lubrication conditions on titanium screw joints for lightweight applications. Tribology International 
$2012 ; 55: 68-76$.

[36] Xu, W, Liu, Z, Cheng, Q, Chen, H, Zhao, Y, Li, Y. A mathematical model of a bolted connection based on Florida contact theory to study the influence of the friction coefficient on structural performance. Advances in Mechanical Engineering 2019; https://doi.org/10.1177/168781 4019851398

[37] F. M Leon, N. G Pai, D. P Hess. Effect of thread dimensional conformance on yield and tensile strength. Engineering Failure Analysis 2001; 8:49-56. 
Figures

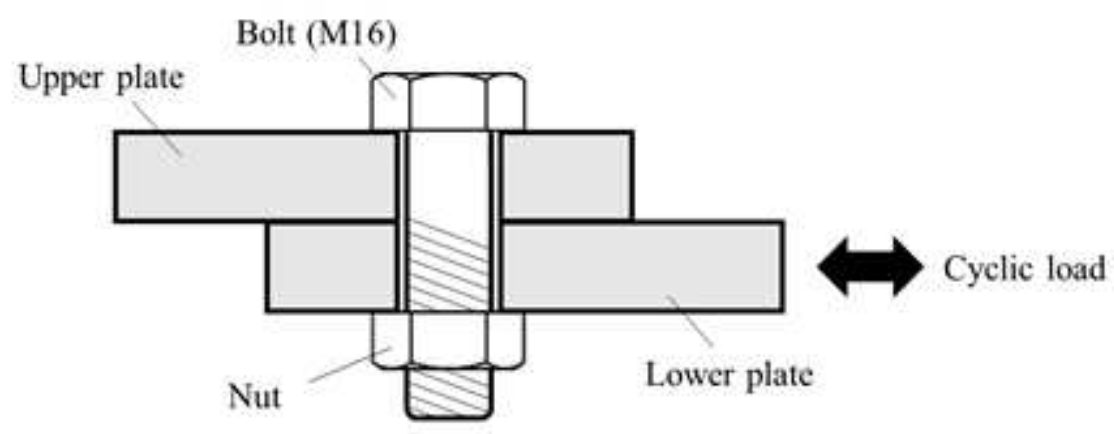

Figure 1

Bolted test sample 


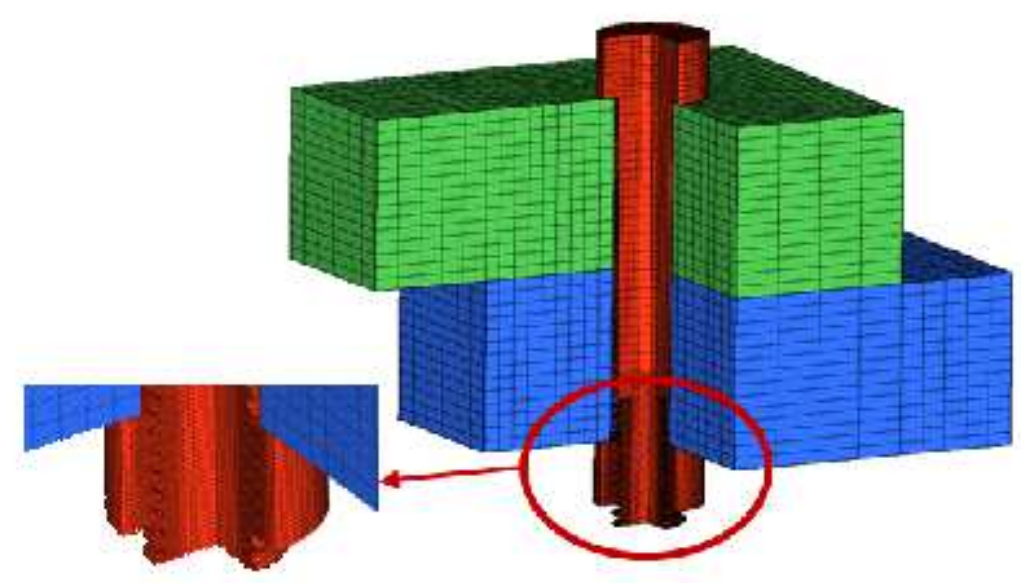

(a) Meshing of FE model

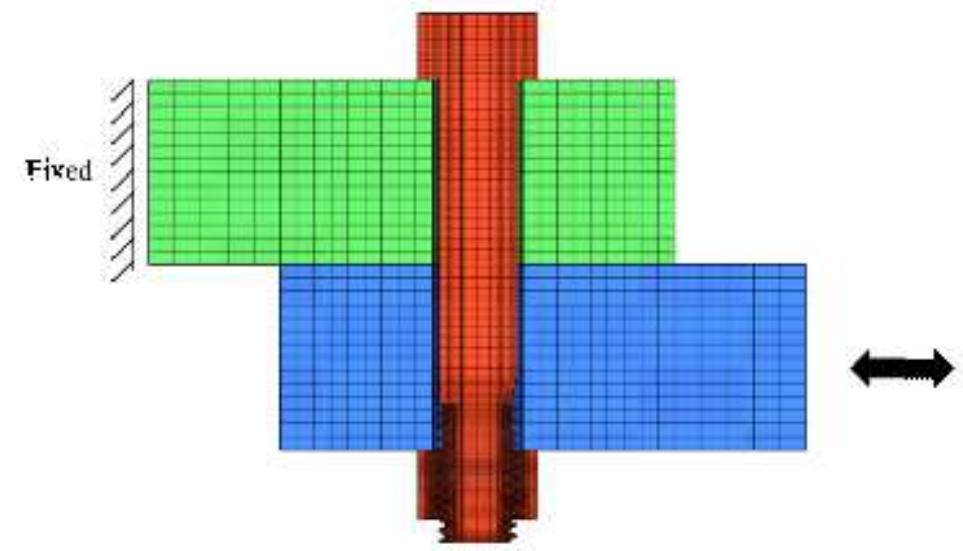

(b) Boundary condition

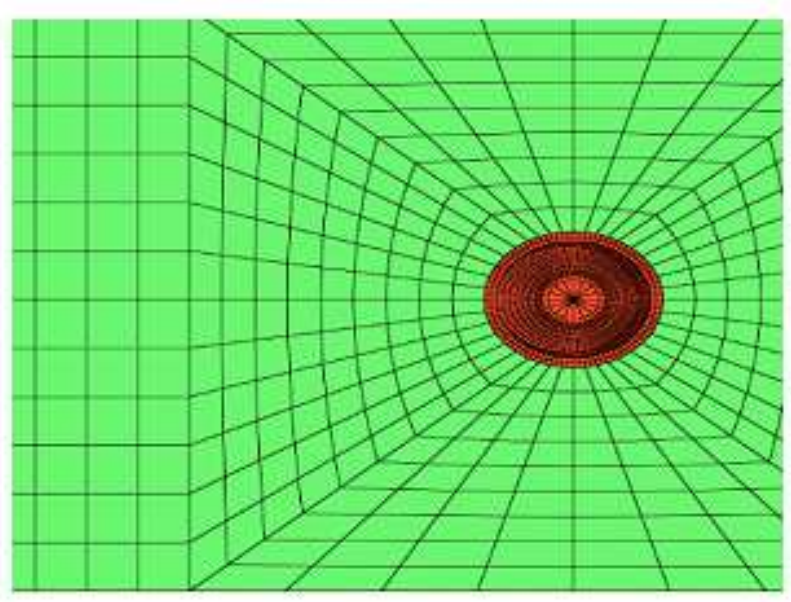

(c) Contact surface

Figure 2

Numerical model. 


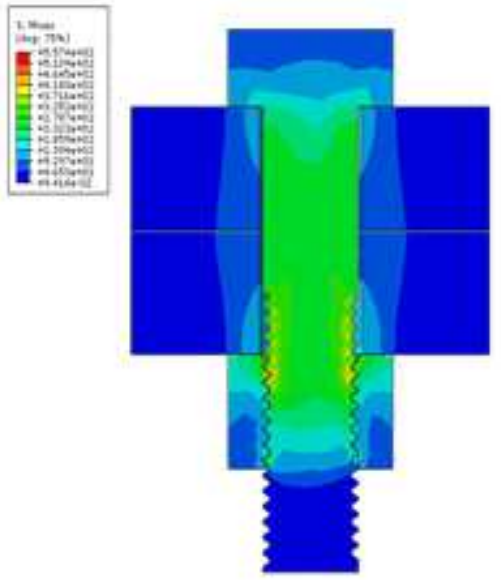

Figure 3

Stress distribution on bolted connection

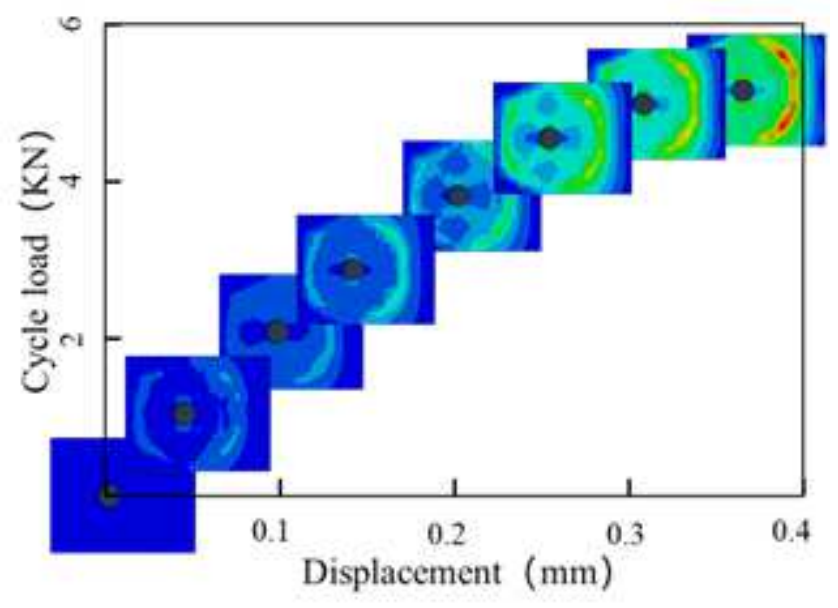

Figure 4

Evolution of fretting slip on the joint surface

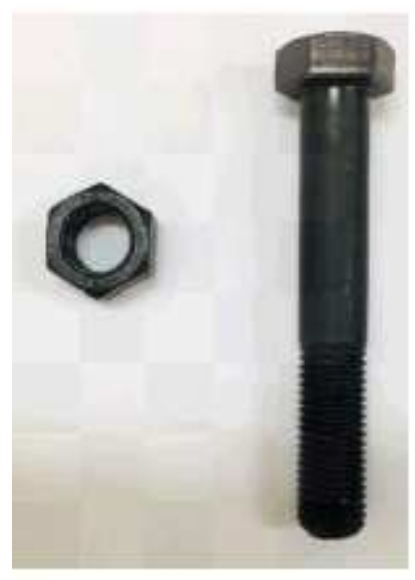

(a) Single bolt and nut

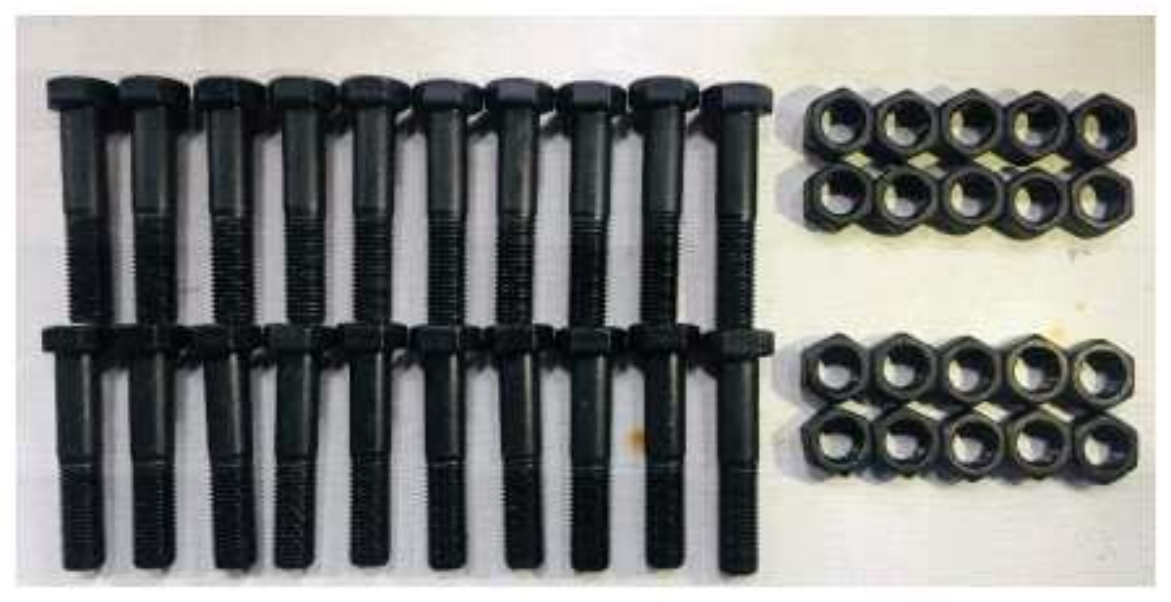

(b) 20 sets of bolts and nuts

Figure 5 
Bolts and nuts after treatment

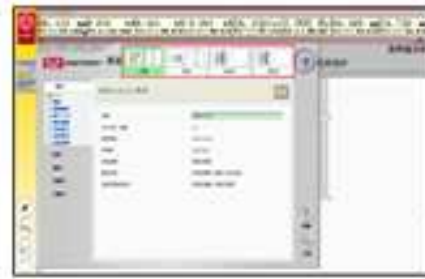

Experimental system control program

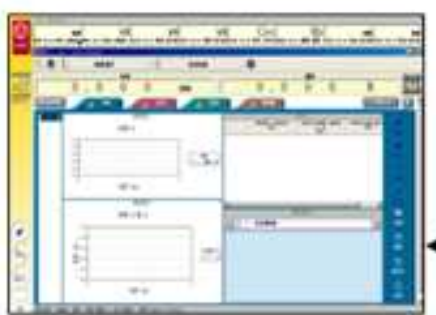

Dynamic experimental test program
Single bolt connection test plece
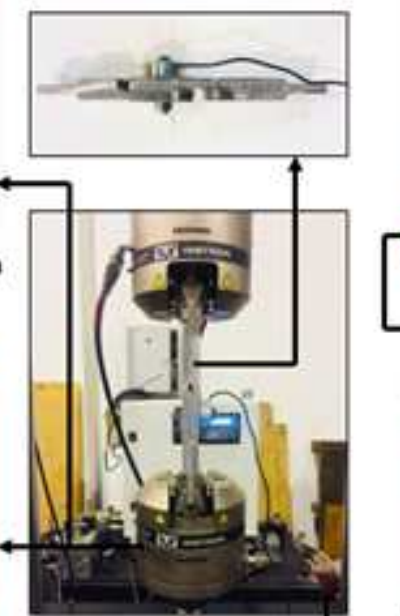

Bolt connection dynamic test system

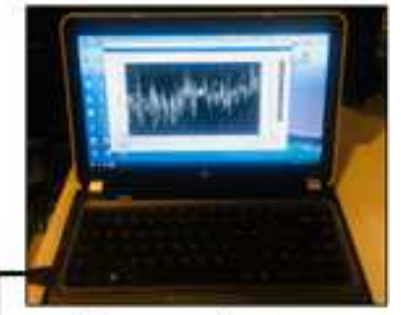

Data processing system

Data collection system

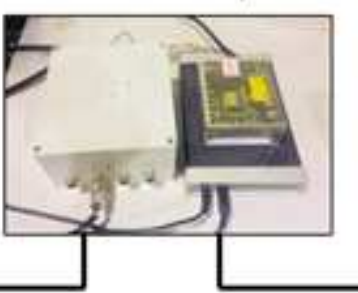

\section{Figure 6}

Bolt relaxation test connecting device

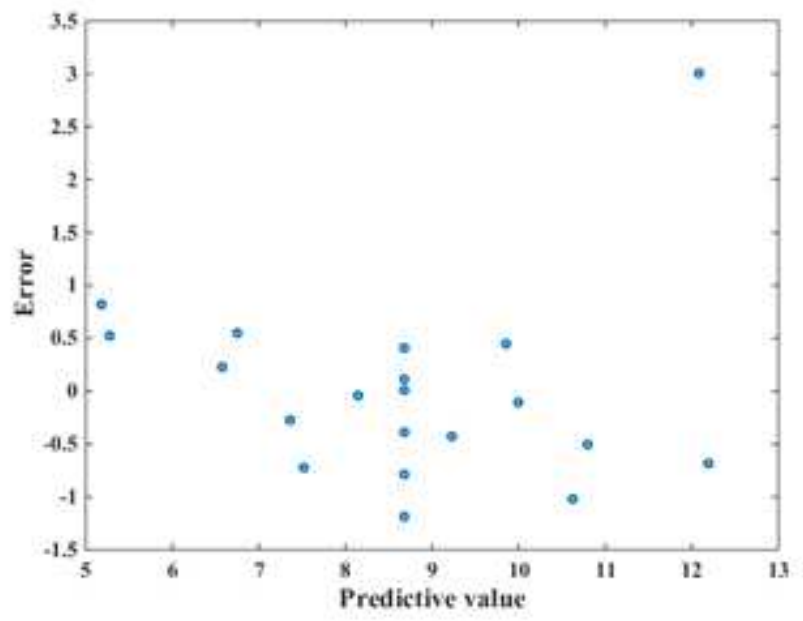

Figure 7

Residual scatter plot of bolt preload attenuation rate 


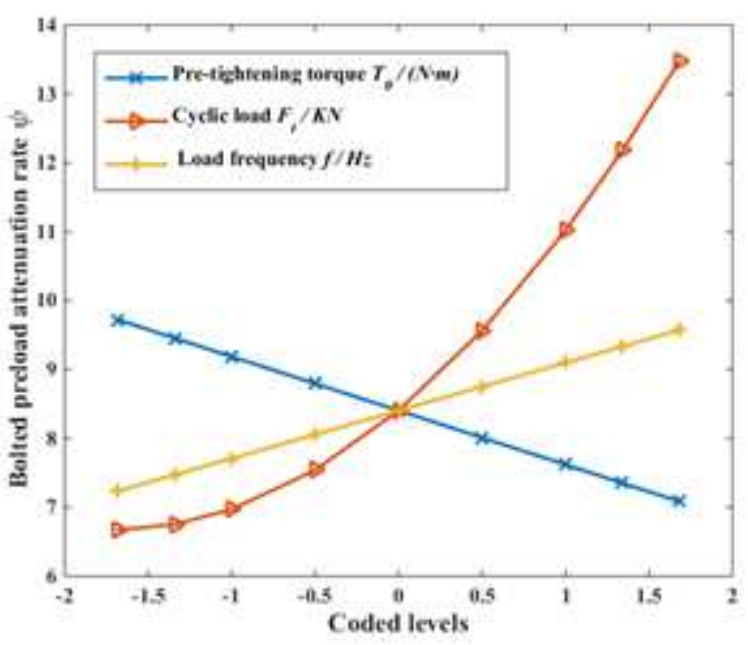

Figure 8

Residual spot diagram of bolt preload attenuation rate 


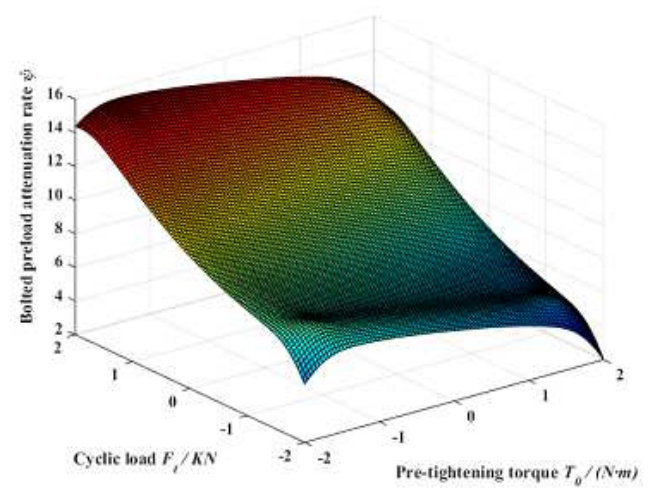

(a) The interaction of $x_{1}$ and $x_{2}$ on the bolt preload attenuation rate

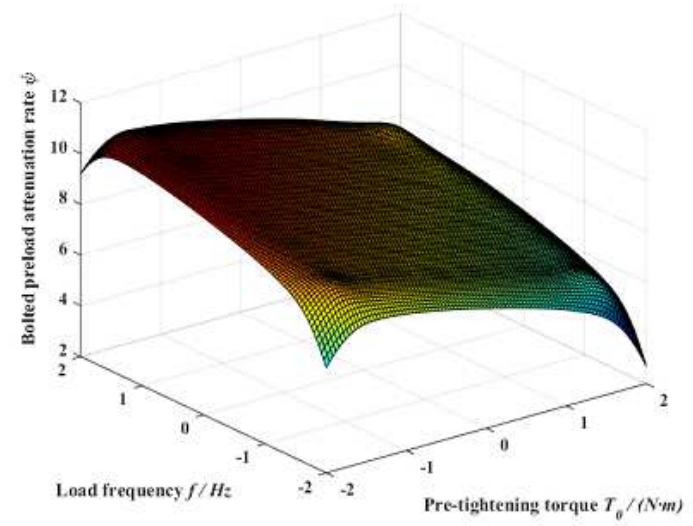

(b) The interaction of $x_{1}$ and $x_{3}$ on the bolt preload attenuation rate

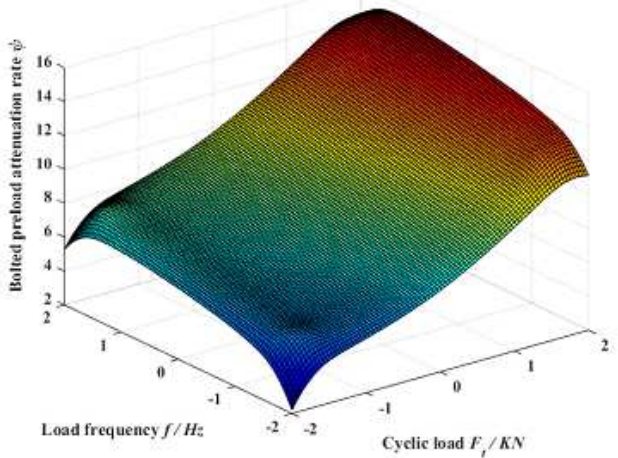

(c) The interaction of $x_{2}$ and $x_{3}$ on the bolt preload attenuation rate

\section{Figure 9}

Interaction of different working factors on the bolt preload attenuation rate. 